\title{
Evaluation of Virulence of Phakopsora pachyrhizi and P. meibomiae Isolates
}

\author{
M. R. Bonde, S. E. Nester, C. N. Austin, C. L. Stone, and R. D. Frederick, USDA-ARS, Foreign Disease-Weed \\ Science Research Unit, Fort Detrick, MD 21702-5023; G. L. Hartman, USDA-ARS and Dept. of Crop Sciences, \\ University of Illinois, Urbana 61801; and M. R. Miles, USDA-ARS, University of Illinois, Urbana 61801
}

\begin{abstract}
Bonde, M. R., Nester, S. E., Austin, C. N., Stone, C. L., Frederick, R. D., Hartman, G. L., and Miles, M. R. 2006. Evaluation of virulence of Phakopsora pachyrhizi and P. meibomiae isolates. Plant Dis. 90:708-716.

Asian soybean rust (ASR), caused by Phakopsora pachyrhizi and recently discovered for the first time in continental United States, has been of concern to the U.S. agricultural industry for more than 30 years. Since little soybean rust resistance is known, and resistance is often difficult to detect or quantitate, we initiated a project to develop a better, more quantitative, method. The methodology determined the average numbers and diameters of uredinia in lesions that developed on leaves of inoculated plants 14 days after inoculation. It was used to compare virulence of $P$. pachyrhizi isolates from Asia and Australia and P. meibomiae from Puerto Rico and Brazil, collected as many as 30 years earlier, with isolates of $P$. pachyrhizi recently collected from Africa or South America. Susceptible reactions to $P$. pachyrhizi resulted in tan-colored lesions containing 1 to 14 uredinia varying greatly in size within individual lesions. In contrast, on these same genotypes at the same time of year, resistance to other $P$. pachyrhizi isolates was typified by 0 to 6 small uredinia in reddish-brown to dark-brown lesions. Using appropriate rust resistant and rust susceptible genotypes as standards, examination of uredinia 14 days after inoculation allowed quantitative comparisons of sporulation capacities, one measure of susceptibility or resistance to soybean rust. The study verified the presence and ability to detect all known major genes for resistance to soybean rust in the original sources of resistance. It demonstrated that soybean lines derived from the original PI sources, and presumed to possess the resistance genes, in actuality may lack the gene or express an intermediate reaction to the rust pathogen. We suggest that a determination of numbers and sizes of uredinia will detect both major gene and partial resistance to soybean rust.
\end{abstract}

Additional keywords: disease resistance, pathogen virulence, resistance screening, soybean rust histology

Asian soybean rust (ASR), incited by Phakopsora pachyrhizi Sydow, has been known in Asia since at least 1902 (9). In

Corresponding author: M. R. Bonde

E-mail: morris.bonde@ars.usda.gov

Current address of C. N. Austin: 334 Plant Science Building, Dept. of Plant Pathology, Cornell University, Ithaca, NY 14853.

This research was partially funded by a grant from the United Soybean Board as Project 2229 to the USDA-ARS, under Specific Cooperative Agreement 58-1920-2-219 and by USDA-ARS-CRIS 1920-22000-027-00D.

The use of trade, firm, or corporation names in this publication is for the information and convenience of the reader. Such use does not constitute an official endorsement or approval by the United States Department of Agriculture or the Agricultural Research Service of any product or service to the exclusion of others that may be suitable.

Accepted for publication 11 January 2006.

DOI: 10.1094/PD-90-0708

This article is in the public domain and not copyrightable. It may be freely reprinted with customary crediting of the source. The American Phytopathological Society, 2006. losses in the northern districts of the state of Karnataka, India (24). An estimate of direct loss caused by rust in Brazil in 2003 is US\$2.0 billion (35).

In 1976, Vakili and Bromfield (32) discovered rust on soybean in the Limani Valley, Puerto Rico. Although they believed that the pathogen was $P$. pachyrhizi, they recognized that Puerto Rican isolates were considerably less virulent and produced fewer urediniospores on soybean than isolates from the Eastern Hemisphere.

Rust pathologists became aware that soybean rust actually was caused by at least two species when Ono et al. (22) in 1992 published a comprehensive paper on the morphology of the Phakopsora species on legumes. In their paper, which clarified the relationships of rust pathogens on legumes, they referred to the rust pathogen on soybeans in the New World as Phakopsora meibomiae (Arthur) Arthur, which had been known to be present on nonsoybean legumes since 1899 (22). Frederick et al. (5) in 2002 confirmed that two species caused soybean rust when they showed that isolates of $P$. meibomiae and $P$. pachyrhizi shared only $80 \%$ nucleotide sequence similarity within the ribosomal internal transcribed spacer region, and they developed polymerase chain reaction assays that differentiated the two species (5).

Bromfield (1) and Bromfield and Hartwig (2) described three infection types on soybean accessions inoculated with $P$. pachyrhizi: 1, RB, reddish-brown lesions with few uredinia and meager sporulation; 2, Tan, tan lesions with many uredinia and abundant sporulation; and, 3, Immune, lack of visible infection. All soybean accessions produced an $\mathrm{RB}$ reaction when inoculated with the organism from Puerto Rico, thought to be P. pachyrhizi and now known to be $P$. meibomiae $(1,2)$.

Bromfield and Hartwig (2), and Hartwig and Bromfield (8) used P. pachyrhizi isolates India 73-1, Taiwan 72-1, Australia 72-1, and Philippines 77-1 to characterize rust reaction phenotypes and screen for resistant soybean lines. Accessions PI 200492 and PI 462312 gave immune and resistant (reddish brown hypersensitive) reactions, respectively, to India 73-1, but were susceptible (with tan colored lesions) to Taiwan 72-1 (8). PI 230970 was resistant to all isolates $(1,8)$, but later was found to be susceptible to a new isolate, 
Taiwan 80-2 (1,7). Subsequently, a soybean introduction from central China, PI 459025, was identified as being resistant to Taiwan 80-2 (1,7). Four independently inherited genes for resistance to $P$. pachyrhizi (Rpp 1-4) were determined to be present in PI 200492 (Rpp 1), PI 230970 (Rpp 2), PI 462312 (cv. Ankur) (Rpp 3), and PI 459025 (Rpp 4), respectively $(1,2,7,8)$.

Screening soybean germ plasm for rust resistance, and developing rust resistant cultivars, has been ongoing in Asia for several decades $(3,6,17,18,20,24,27-31)$. For example, in the People's Republic of China (PRC), cultivars bred for resistance to $P$. pachyrhizi include You dou $84-87$, Zan Bian \#1, and Liu-dou \#1 (3,20). 'September Yellow' has been widely promoted as rust tolerant in Datian county, Fujian province, PRC (30), and 'Baihua Jiuyuehuang' was part of the integrated control strategy for soybean rust in PRC (15).

Initially, the objective of this study was to characterize reaction phenotypes based on symptom expression as described by Bromfield and Hartwig (2) and relate this to pathogen development within plant leaves. It was our hypothesis that numbers of uredinia per lesion and average uredinia diameters are reflections of the growth of the pathogen in host tissue, and as such could be used as quantitative measures of susceptibility or resistance to soybean rust, similar to measurements of spore producing capacity with wheat rust pathogens (23). During our study, $P$. pachyrhizi was discovered in South America for the first time, causing alarm throughout the U.S. soybean industry (19). As a result, we extended our study to compare virulence of Asian and Australian isolates collected as much as three decades earlier with newly collected isolates from Africa, South America, or Hawaii. These comparisons should provide insight into whether or not $P$. pachyrhizi had significantly changed in virulence, and the data from this study will supply valuable information with which to better screen for rust resistance. With the recent spread of $P$. pachyrhizi to the southeastern United States, it is important that rust resistant cultivars be developed and made available to U.S. growers as soon as possible. Results of studies with U.S. isolates will be included in a future publication.

\section{MATERIALS AND METHODS}

Pathogen isolates. Each isolate was a population of urediniospores harvested from numerous pustules on field-collected soybean leaves from the country and year indicated by the respective isolate designation (Table 1). Urediniospores of each isolate of $P$. pachyrhizi were increased on the soybean cultivar Wayne or Williams, and those of $P$. meibomiae on either red kidney bean (Phaseolus vulgaris L.) or lima bean (Phaseolus lunatus L.), in isolation cubicles or greenhouses. Subsamples of all isolates were stored in liquid nitrogen $\left(-196^{\circ} \mathrm{C}\right)$ refrigerators at the USDA, ARS, Foreign Disease-Weed Science Research Unit (FDWSRU) Biological Safety Level 3 (BSL3-P) Containment Facility (12). Harvesting urediniospores from infected leaves during spore increases was by a vacuum-type harvester (4), beginning 10 to 14 days after inoculation and continuing at weekly intervals.

Plant accessions and propagation. The soybean cultivars Williams, Centennial, and Wayne were used in the study as highly susceptible controls. Also used were the rust resistant accessions Tainung \#4 (Nung-shih H $11 \times$ PI 200492), Plant Introduction (PI) accessions 200492 (Komata), 230970, 459025B, and 462312 (Ankur), and the putative rust resistant lines D86-8286 (Rpp 3) (10) and D91-5987 (Rpp 4) (10). Plants were grown two per $10.2-\mathrm{cm}$-diameter clay pot. During the course of the study, plants were fertilized as needed with 14-14-14 Osmocote (Scotts-Sierra Horticultural Products Co., Marysville, $\mathrm{OH}$ ).

Inoculation of plants. One day prior to inoculation, urediniospores were removed from liquid nitrogen storage, heat shocked while dry for $5 \mathrm{~min}$ at $40^{\circ} \mathrm{C}$, and then hydrated for $16 \mathrm{~h}$ at $100 \%$ relative humidity

Table 1. Reaction types on commercial cultivars, breeding lines, and plant introduction accessions 14 days after inoculation with isolates of Phakopsora pachyrhizi or P. meibomiae ${ }^{\text {a }}$

\begin{tabular}{|c|c|c|c|c|c|c|c|c|c|}
\hline $\begin{array}{c}\text { Pathogen } \\
\text { Isolate }^{\text {b }}\end{array}$ & Williams $^{c}$ & Wayne $^{c}$ & $\begin{array}{c}\text { Komata }^{\mathrm{d}} \\
\operatorname{Rpp} 1\end{array}$ & $\begin{array}{c}230970 \\
\operatorname{Rpp} 2\end{array}$ & $\begin{array}{c}\text { Ankur }^{\mathrm{e}} \\
\operatorname{Rpp} 3\end{array}$ & $\begin{array}{c}\text { 459025B }^{\mathrm{f}} \\
\operatorname{Rpp} 4\end{array}$ & $\begin{array}{c}\text { Tainung\#4g } \\
\text { Rpp1 + }\end{array}$ & $\begin{array}{c}\text { D86-8286 }^{\mathrm{h}} \\
\operatorname{Rpp}^{3}\end{array}$ & $\begin{array}{c}\text { D91-5987 } \\
\quad \operatorname{Rpp} 4\end{array}$ \\
\hline \multicolumn{10}{|l|}{ P. pachyrhizi } \\
\hline Taiwan 72-1 & Tan & Tan & Tan & $\mathrm{RB}$ & Tan/RB & Inter & Tan & $\mathrm{RB}$ & Tan \\
\hline Taiwan 80-1 & Tan & Tan & Tan & $\mathrm{RB}$ & Tan & Inter & Tan & $\mathrm{RB}$ & Tan \\
\hline Taiwan 80-2 & Tan & Tan & Tan & Tan & Tan & $\mathrm{RB}$ & $\mathrm{ND}^{\mathrm{j}}$ & TAN & Tan \\
\hline Philippines 77-1 & Tan & Tan & Tan & $\mathrm{RB}$ & Tan & $\mathrm{RB}$ & Inter & TAN & Tan \\
\hline Australia 79-1 & Tan & Tan & Immune & $\mathrm{RB}$ & $\mathrm{RB}$ & $\operatorname{Tan}^{\mathrm{k}}$ & Immune & TAN & Tan \\
\hline India 73-1 & Tan & Tan & Immune & Inter & $\mathrm{RB}$ & $\mathrm{RB}$ & Immune & Tan/RB & Tan \\
\hline Hawaii 94-1 & Tan & Tan & Immune & RB & $\mathrm{Imm} / \mathrm{RB}^{1}$ & $\mathrm{RB}$ & Immune & Tan/RB & Tan \\
\hline Thailand 01-1 & Tan & Tan & Tan & Inter & Tan & $\mathrm{RB}$ & Tan & $\mathrm{RB}$ & Tan \\
\hline Zimbabwe 01-1 & Tan & Tan & Tan & Inter & Tan & Inter & Tan & Tan & Tan \\
\hline South Africa 01-1 & Tan & Tan & Tan & $\mathrm{RB}$ & $\mathrm{RB}$ & Inter & $\mathrm{RB}$ & Inter & Tan \\
\hline Brazil 01-1 & Tan & Tan & Tan & Inter & Mixed & $\mathrm{RB}$ & Mixed & Tan & Tan \\
\hline Paraguay 01-2b & Tan & Tan & Tan & RB & Mixed & $\mathrm{RB}$ & $\mathrm{RB}$ & Tan & Tan \\
\hline \multicolumn{10}{|l|}{ P. meibomiae } \\
\hline Brazil 82-1 & $\mathrm{RB}$ & $\mathrm{RB}$ & $\mathrm{RB}$ & Immune & Immune & $\mathrm{RB}$ & Immune & Immune & $\mathrm{RB}$ \\
\hline Puerto Rico 76 & $\mathrm{RB}$ & $\mathrm{RB}$ & $\mathrm{RB}$ & RB & $\mathrm{RB}$ & $\mathrm{RB}$ & $\mathrm{RB}$ & $\mathrm{RB}$ & $\mathrm{RB}$ \\
\hline
\end{tabular}

a Soybean plants at the two- to four-trifoliolate leaf stage were atomized with a suspension of 1 to $2 \times 10^{4}$ urediniospores per ml of $0.01 \%$ Tween 20 in distilled water and incubated overnight in a dew chamber at $20^{\circ} \mathrm{C}$. At 14 days after inoculation, leaflets were examined at $\times 10$ magnification to determine reaction types. Reaction types were: 1, Tan, tan-colored lesions with 1 to 14 uredinia per lesion; 2, RB, reddish brown hypersensitive lesions with 0 to 6 uredinia per lesion; and 3, Immune, no visible symptoms. Tan/RB indicates that some plants produced a Tan reaction and some an RB reaction either within or between experiments. Mixed indicates Tan and RB reactions were evident on the same individual plants. Intermediate (Inter) indicates a reaction type somewhere between Tan and RB in the single experiment (experiment 3) where tested.

b Pathogen isolates are designated based on country and year of origin.

c U.S. commercial cultivars.

d Cultivar Komata (PI 200492) with Rpp 1 gene for resistance to soybean rust.

e Cultivar Ankur (PI 462312), grown in India in the 1970s, with the Rpp 3 gene for resistance to soybean rust.

f Selection from original PI 459025 with Rpp 4 gene for soybean rust resistance.

g Cultivar Tainung \#4, with the Rpp 1 gene, and believed to have an additional gene for resistance (18).

${ }^{\mathrm{h}}$ Breeding line selection reputed to have Rpp 3 gene for rust resistance.

i Breeding line selection reputed to have the Rpp 4 gene for rust resistance. The cross was initially between the cultivar Hardee and PI 459025 . An advanced F3 line was crossed with the variety Lamar and advanced to the F5 generation. Results from this study indicate the gene is not present.

j $\mathrm{ND}=$ not done.

${ }^{\mathrm{k}}$ Although scored as Tan, the low spore producing area per lesion suggests an $\mathrm{RB}$ reaction.

${ }^{1}$ In experiment 2, plants reacted with an immune reaction, and in experiment 3 an RB reaction. 
over water in a glass desiccator at room temperature. Hydrated urediniospores were suspended in sterile distilled water containing one drop of Tween 20 per $100 \mathrm{ml}$ to a final concentration of $1 \times 10^{4}$ or $2 \times$ $10^{4}$ per ml. Two and one-half milliliters of the urediniospore suspension was sprayed onto two plants at the two- to fourtrifoliolate-leaf stage in each of one or two 10.2-cm-diameter clay pots per soybean accession. All plants were maintained overnight (approximately $16 \mathrm{~h}$ ) in dew chambers at $20^{\circ} \mathrm{C}$. After the dew treatment, plants were removed from the chambers, allowed to dry, and then placed in a greenhouse maintained at 20 to $25^{\circ} \mathrm{C}$ for disease development. Experiment 1 was conducted from 19 September to 3 October 1995, ex-

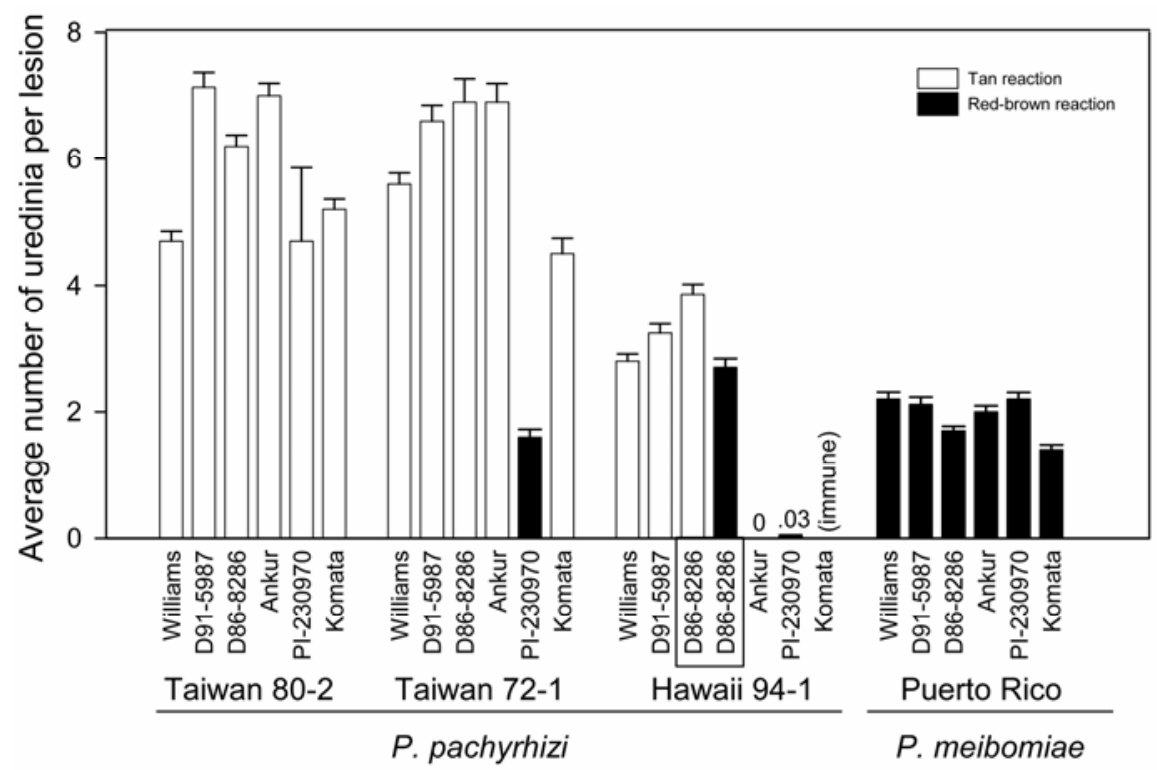

Fig. 1. Average number of uredinia per lesion $(n=100)$ in experiment 2 on cv. Williams, two reputed rust resistant breeding lines, and each of three PI accessions each containing a reputed singe major gene for rust resistance. Accessions were inoculated separately with isolates of Phakopsora pachyrhizi from Taiwan or Hawaii, or P. meibomiae from Puerto Rico. PI 200492, PI 230970, and PI 462312 contain the Rpp 1, Rpp 2, and Rpp 3 genes, respectively, for rust resistance. Bracket signifies that not all plants of the accession inoculated with isolate Hawaii 94-1 were scored as having the same reaction type. Hawaii 94-1 produced a Tan reaction on one D86-8286 plant and an RB reaction on three other plants. Error bars represent standard errors of the means.

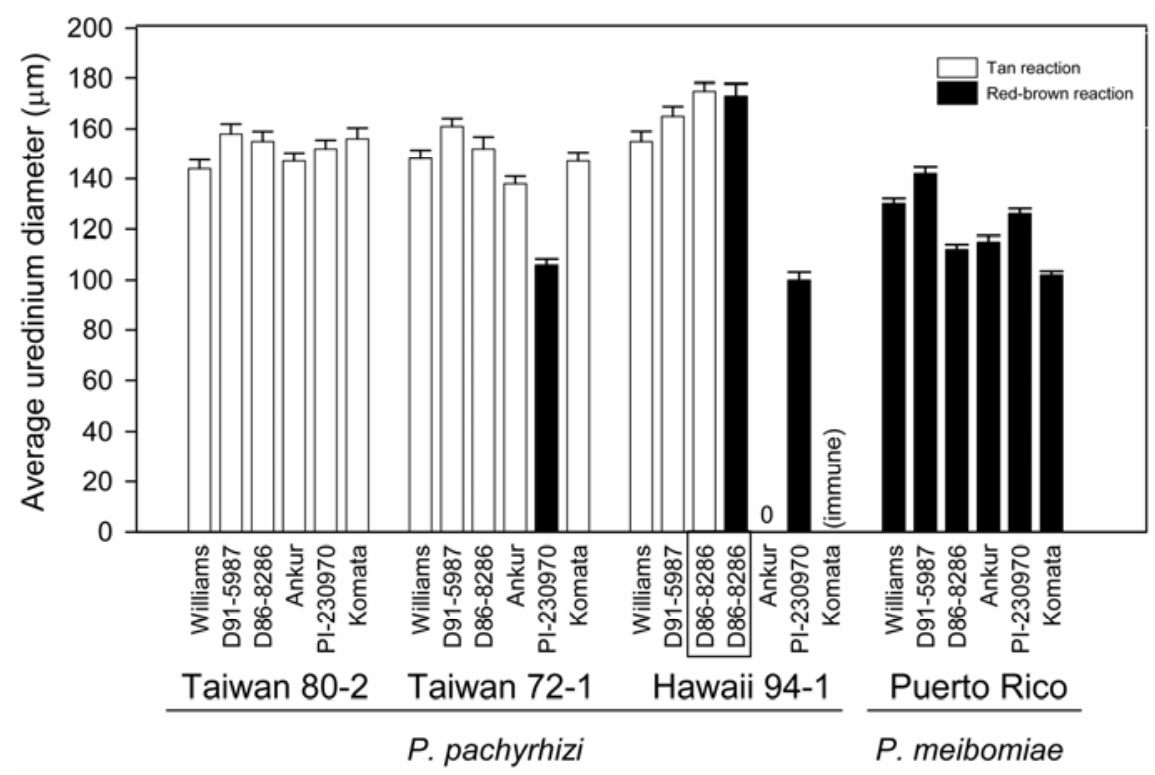

Fig. 2. Average uredinium diameter $(\mu \mathrm{m})(n=100)$ for $\mathrm{cv}$. Williams, two reputed rust resistant breeding lines, and each of three rust resistant PI accessions containing single genes for rust resistance inoculated separately with isolates of Phakopsora pachyrhizi from Taiwan or Hawaii, or P. meibomiae from Puerto Rico. PI 200492, PI 230970, and PI 462312 contain the Rpp 1, Rpp 2, and Rpp 3 genes, respectively, for rust resistance. Bracket signifies that not all plants of the accession inoculated with isolate Hawaii 94-1 were scored as having the same reaction type. Hawaii 94-1 produced a Tan reaction on one D86-8286 plant and an RB reaction on three other plants. Error bars represent standard errors of the means.

periment 2 from 3 to 17 April 1996, and experiment 3 from 21 February to 8 March 2002. The second experiment was conducted at a time when environmental conditions apparently were more conducive for disease development, based on subsequent density of lesions, than the other times.

Determination of infection types. In each experiment, 14 days after inoculation, the two or four test plants per soybean accession/pathogen isolate were examined to determine symptoms at $\times 1$ and $\times 15$ magnification in the greenhouse and scored using the criteria of K. R. Bromfield (1) as having a Tan, RB, or Immune reaction phenotype. Tan-colored lesions (designated Tan reaction), the color primarily due to the large numbers of tan urediniospores, indicated a highly susceptible reaction, and reddishbrown lesions (designated RB reaction), a form of resistance (1). An immune reaction (designated Immune) indicated a lack of obvious symptoms (1). In some instances, an intermediate, weakly hypersensitive response with moderate sporulation (designated Intermediate) was produced. If two reaction types were expressed on the same plant, generally on the same leaflet, the reaction was designated as Mixed and assumed to be the result of a mixture of races in the inoculum.

Histological comparisons. At 14 days after inoculation, leaflets from the test plants of each accession inoculated with $P$. pachyrhizi or P. meibomiae, and previously examined for reaction phenotype, were excised from the plants, and leaf pieces approximately $1 \times 1 \mathrm{~cm}$ placed into a solution of absolute ethanol/acetic acid (3:1, $\mathrm{vol} / \mathrm{vol}$ ) for at least $24 \mathrm{~h}$ to fix and remove plant pigments from the tissue. The leaf pieces were transferred to lactophenol for $24 \mathrm{~h}$ to further clear the tissue and make translucent, and stained in $0.1 \%$ cotton blue in lactophenol for $24 \mathrm{~h}$. The stained leaf pieces were examined microscopically at $\times 100$ and $\times 400$ and measurements of uredinia made with an ocular micrometer as described below.

Experimental design. Leaf samples for each soybean accession/rust isolate were combined within an experiment. For experiment 1 (data not presented), in which specific parameters were tested to determine their potential for detecting resistance, all combinations of seven rust isolates and 10 soybean accessions were examined 14 days after inoculation. Data included uredinia diameter, number of uredinia per lesion, number of uredinia per $\mathrm{mm}^{2}$ lesion area, and reaction type (i.e., Tan, RB, or Immune). Sample size for each parameter, other than reaction type, was 100 , and measurements were obtained from randomly selected leaf pieces collected from the two or four inoculated plants, depending upon the number of plants in a particular experiment.

In experiment 2 (Table 1, Figs. 1 and 2), four rust isolates were inoculated onto six 

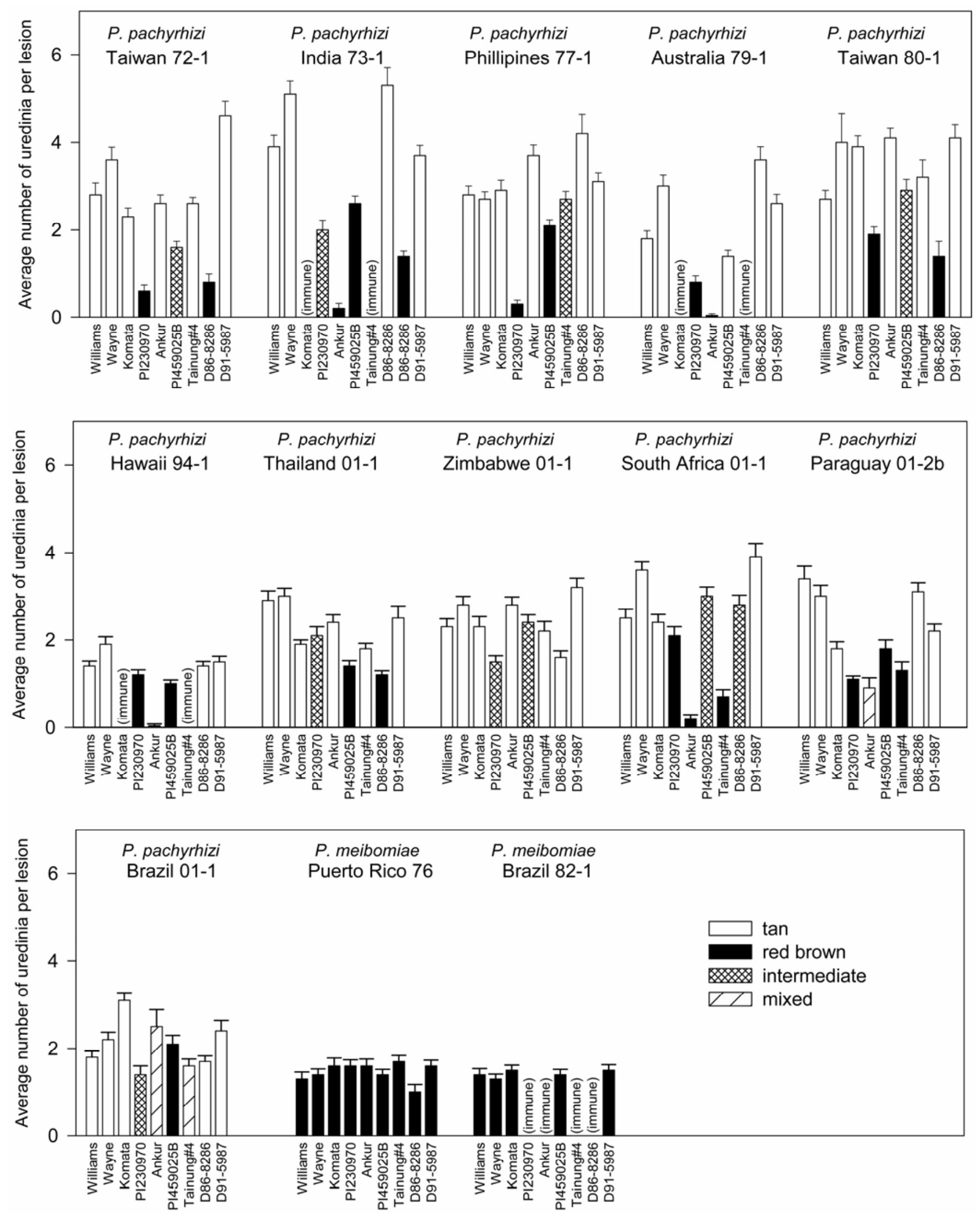

Fig. 3. Average number of uredinia per lesion $(n=25) 14$ days after inoculation with 11 separate isolates of Phakopsora pachyrhizi or two of P. meibomiae. Cultivars Williams and Wayne are representative U.S. cultivars highly susceptible to Asian Soybean Rust. The Japanese cultivar Komata (PI 200492) and the Taiwanese cultivar Tainung \#4 (PI 368039) contain the Rpp 1 gene for soybean rust resistance, PI 230970 the Rpp 2 gene, and Indian cultivar Ankur (PI 462312) the Rpp 3 gene. Breeding line D86-8286 (10) is reputed to contain Rpp 3 and D91-5987 Rpp 4 (10). Note that the latter had a large number of uredinia per lesion and always produced a Tan reaction. 

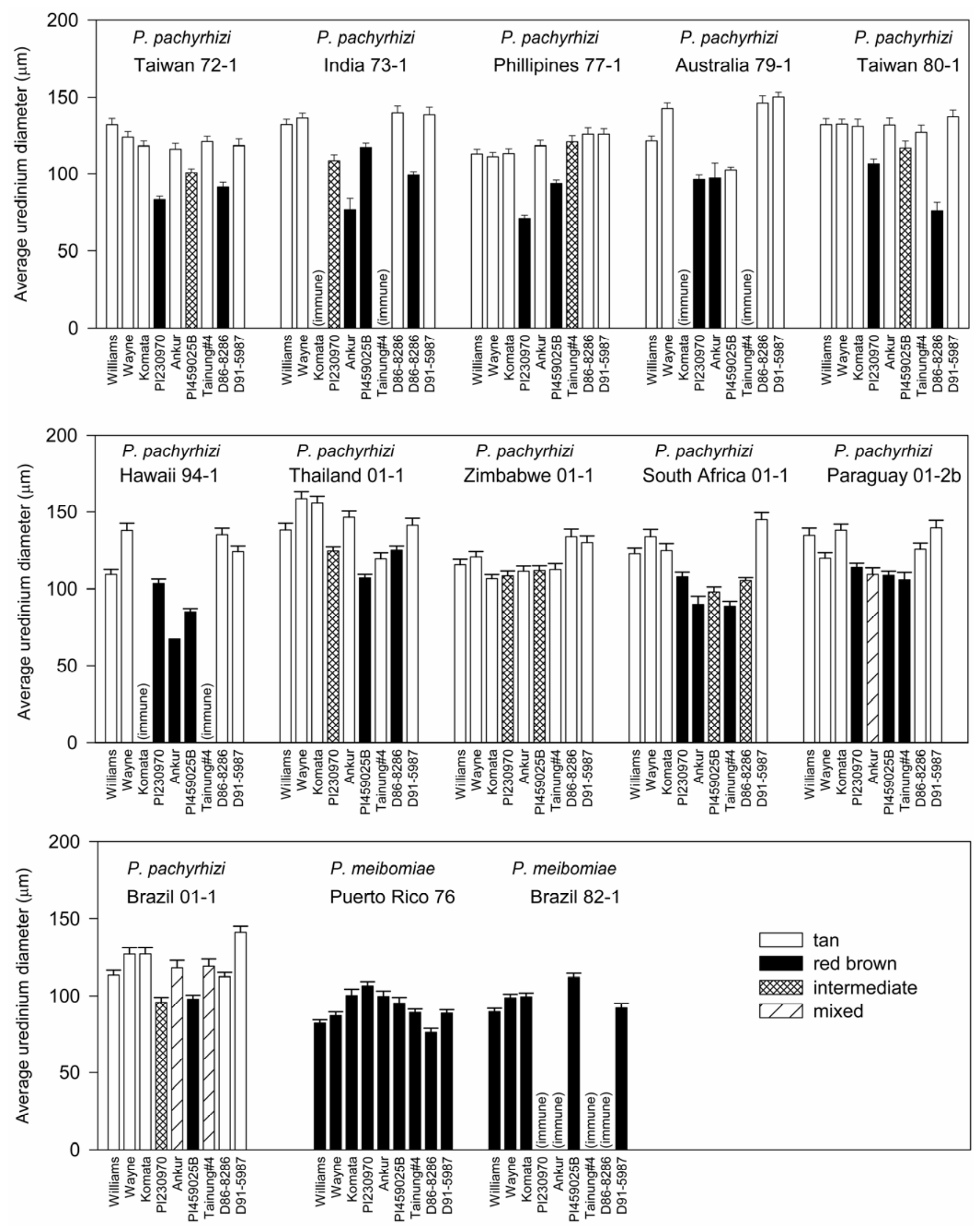

Fig. 4. Average uredinium diameter $(n=50)$ at 14 days after inoculating 11 isolates of Phakopsora pachyrhizi and two of P. meibomiae separately onto nine soybean accessions. Cultivars Williams and Wayne are representative U.S. cultivars highly susceptible to Asian Soybean Rust. The Japanese cultivar Komata (PI 200492) and the Taiwanese cultivar Tainung \#4 (PI 368039) contain the Rpp 1 gene for soybean rust resistance, PI 230970 the Rpp 2 gene, and Indian cultivar Ankur (PI 462312) the Rpp 3 gene. Breeding line D86-8286 (10) is reputed to contain Rpp 3 and D91-5987 Rpp 4 (10). Note that D91-5987 had relatively large uredinia diameters and lesions were Tan, regardless of pathogen isolate used for inoculum. 
soybean accessions. Data included reaction type, uredinia diameter, and number of uredinia per lesion; sample size for the latter two each was 100 .

In experiment 3 (Table 1, Figs. 3 and 4), 13 rust isolates, including five not available for use in previous experiments, were inoculated separately onto each of nine soybean accessions. Besides reaction type, data included uredinia diameter and number of uredinia per lesion. Sample size was 25 lesions to determine number of uredinia per lesion, and 50 uredinia to determine average uredinia diameter for each pathogen isolate/soybean accession.

In each experiment, the means and standard errors of the means were calculated for each parameter.

\section{RESULTS}

Lesion size. Lesion diameters, determined in experiment 1 for 70 pathogen isolate/soybean accession combinations, were not correlated with resistance or susceptibility. Often, RB reactions produced the largest lesions. Tan lesions frequently were difficult to measure. As a result, this parameter was not included in subsequent experiments.

Reaction phenotypes. Reaction phenotypes (Fig. 5) in our study generally were consistent for each of the PI accessions inoculated with the specific isolates used previously to describe the four known $R p p$ genes $(1,2,7,8$; Table 1). Furthermore, $P$. pachyrhizi isolates Taiwan 72-1, India 731, Australia 79-1, and Taiwan 80-2; and $P$. meibomiae isolate Puerto Rico 76 produced for us essentially the same reaction on each of the four PI accessions as they did for Bromfield and Hartwig (2), Hartwig (7), and Hartwig and Bromfield (8). The only exceptions were in a few instances in which we interpreted a reaction to be intermediate (between Tan and RB), instead of $\mathrm{RB}$ as reported previously by Hartwig and Bromfield (8).

Our results with soybean line D86-8286, however, were inconsistent among experiments, and sometimes within an experiment (Table 1). For example, in experiment 3, one D86-8286 plant inoculated with India 73-1 produced obvious Tan lesions and one clearly RB lesions (Figs. 3 and 4). Likewise, in experiment 2, one D86-8286 plant produced a Tan reaction while three plants gave an $\mathrm{RB}$ reaction when inoculated with Hawaii 94-1 (Figs. 1 and 2). It was difficult to distinguish between Tan and RB on these plants, and the histological measurements indicated little or no difference among plants.

Although reaction phenotypes usually grouped into either Tan or RB, each pathogen isolate produced its own characteristic Tan or RB reaction. For example, Hawaii 94-1 in experiment 2 inoculated onto susceptible soybean accessions, lacking major genes for rust resistance, produced a Tan reaction with an average of 2.7 to 3.8 ured- inia per lesion (Fig. 1), and the uredinia varied greatly in size within individual lesions (e.g., Fig. 6A). Isolate Hawaii 94-1 produced uredinia with mean diameters of 155,165 , and $176 \mu \mathrm{m}$ on Williams, D915987, and D86-8286, respectively (Fig. 2).

Hawaii 94-1 on PI 230970 (with the Rpp 2 gene) produced a strong RB reaction (Fig. 6C). No uredinia were evident in at least $97 \%$ of the lesions, and those that were present were small, averaging only $100 \mu \mathrm{m}$ in diameter (Fig. 2). Uredinia often stained poorly with cotton blue (Fig. 6C), and as expected, sporulation was sparse.

Soybean accessions PI 200492 (Komata) and PI 462312 (Ankur), containing the Rpp 1 and Rpp 3 genes, respectively, in experiment 2 were immune to Hawaii 94-1 (Figs. 1 and 2). However, in experiment 3, PI 462312 inoculated with Hawaii 94-1 produced an RB reaction with few uredinia (Fig. 3).

Relationship between number of uredinia and uredinia diameters to Tan, $\mathbf{R B}$, and Immune reactions. Tan reactions usually had higher average numbers of uredinia per lesion (Figs. 1 and 3) and larger average uredinia diameters (Figs. 2 and 4) than typical RB reactions. In experiment 2 , conducted when symptoms were well expressed and differences between resistant and susceptible reactions were great, Tan lesions had 1 to 14 (averages varied from 2.8 to 7.0 ) uredinia per lesion, and RB lesions, excluding those on D86-8286, had 0 to 6 (averages 0.0 to 1.7) uredinia per lesion (Fig. 1). Many RB lesions were devoid of uredinia. Although average diameters of uredinia usually were larger in Tan reactions than in RB reactions, uredinia diameters did not separate pathogen isolate/soybean accession responses to the degree as numbers of uredinia per lesion.

Comparison of $\boldsymbol{P}$. pachyrhizi isolates. In contrast to older isolates collected in Asia and Australia, isolates of $P$. pachyrhizi acquired in 2001 from Africa or South America never caused an Immune reaction on any of the soybean accessions tested. When RB reactions were observed, the number of uredinia per lesion usually was not greatly less than in Tan reactions on the same soybean accession (Fig. 3). In a few instances, an Intermediate reaction was observed in which the reaction was neither RB nor Tan, but intermediate between RB and Tan (Figs. 3 and 4). Based on the lower frequency of $\mathrm{RB}$ reactions and complete absence of Immune reactions on soybean accessions containing the known major genes for rust resistance, the newer isolates from Africa and South America were more virulent and/or aggressive than the older isolates. The most virulent was Zimbabwe 01-1 (Table 1, Figs. 3 and 4), in which no RB or Immune reactions were observed.

Reactions of soybean to $P$. meibomiae. P. meibomiae isolates Puerto Rico 76 and
Brazil 82-1 produced red-brown to darkbrown lesions with few uredinia, or an immune reaction (Table 1). Even during the most conducive time of year for disease, lesions had an average of only 1.4 to 2.2 uredinia per lesion (Fig. 1). Uredinia produced by these two $P$. meibomiae isolates were small, with average diameters ranging from 101 to $142 \mu \mathrm{m}$ when inoculated onto the various soybean accessions (Fig. 2 and 6E).

\section{DISCUSSION}

Knowledge of how a pathogen develops within a plant can be very valuable when evaluating disease resistance. In this paper, we examined the relationships of numbers of uredinia per lesion and average uredinia diameters that developed during expression of the Tan, RB, and Immune reaction phenotypes previously described by Bromfield (1) and Bromfield and Hartwig (2). It was particularly significant that each soybean accession used by them behaved the same, or nearly the same, for us. Because we used the same pathogen isolates, stored in liquid nitrogen refrigerators, as Bromfield (1) and Bromfield and Hartwig (2), we were able to make conclusions otherwise not possible.

It became apparent in our study that the $\mathrm{RB}$ reaction (2) actually is a spectrum of reaction types. $\mathrm{RB}$ lesions, in addition to being reddish brown, were sometimes dark chocolate brown, or even light brown. Whereas RB lesions generally had sparse sporulation, there were a few instances in which RB lesions sporulated prolifically. In the susceptible reactions, Tan lesions also varied. Fully susceptible Tan lesions usually produced more numerous and larger uredinia than RB lesions. The greatest differences between RB and Tan lesions occurred during March to mid-November. This was observed in other soybean rust studies also being conducted in our greenhouses (M. R. Miles, G. L. Hartman, R. D. Frederick, and M. R. Bonde, unpublished data).

Whereas the reaction phenotypes on the original sources were easy to score in this study, it was very difficult to ascertain whether some lines derived from them had $\mathrm{RB}$ or Tan lesions. For example, in experiment 2, not only were the D86-8286 plants inoculated with Hawaii 94-1 difficult to assign as Tan or RB, the numbers of uredinia per lesion and average uredinia diameters within the lesions were very similar (Figs. 1 and 2). This supports our belief that soybean lines derived from the original sources of Rpp 1-4 sometimes produce intermediate reactions.

Average number of uredinia per lesion (Figs. 1 and 3) was a better indicator of reaction phenotype than average uredinia diameter; however, we believe that a combination of the two parameters might be a better and more prudent measure of resistance or susceptibility. This concept is 


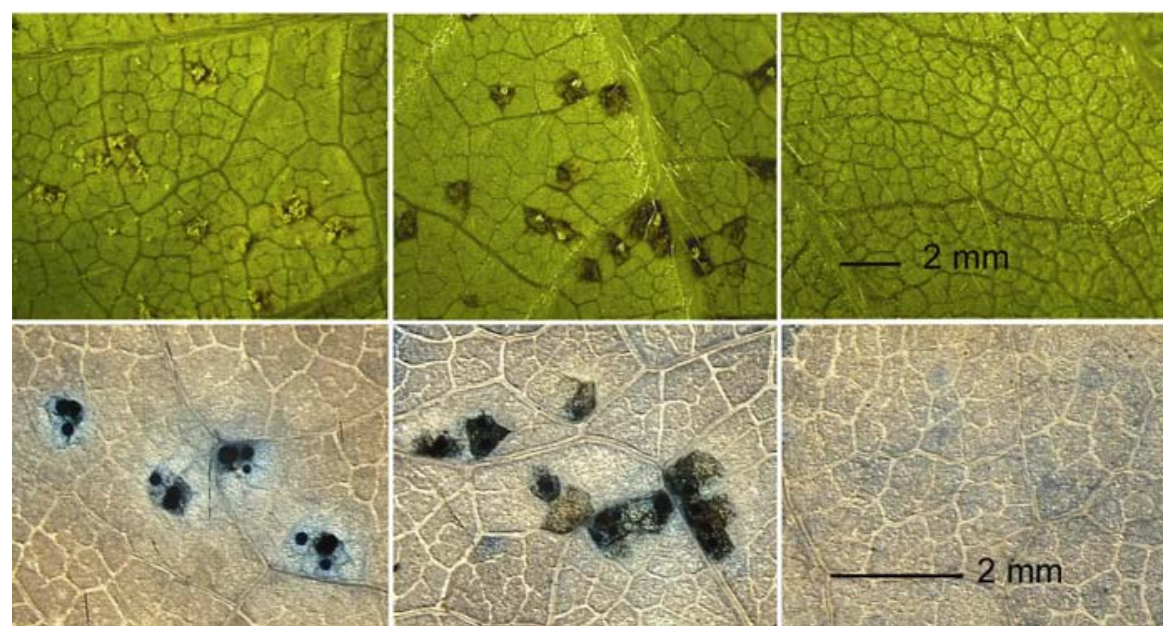

Fig. 5. Typical symptoms of Tan, RB, and Immune reactions 15 days after inoculation (top row); and leaf tissue after removal of pigments and staining with cotton blue (bottom row). Left is Taiwan 80-1 on PI 200492 (Tan reaction), middle Taiwan 80-1 on PI 230970 (RB reaction), and right India 73-1 on PI 200492 (Immune reaction). PI 200492 and PI 230970 contain the Rpp 1 and Rpp 2 genes, respectively, for rust resistance. The top row of illustrations is the lower leaf surface of the fresh leaf, and the bottom row the lower leaf surface of the same combination of pathogen isolate/soybean accession fixed, cleared, and stained with cotton blue.
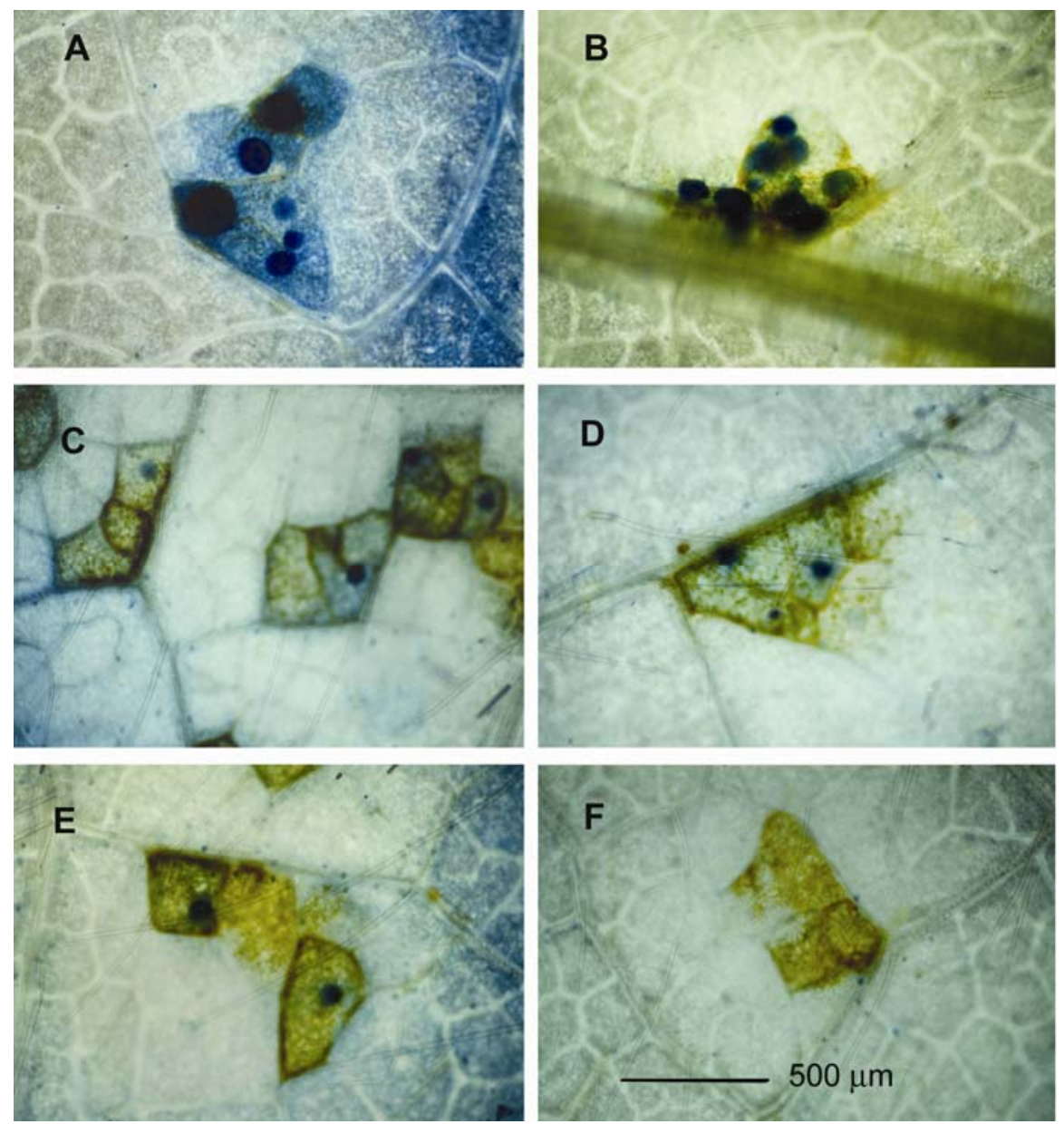

Fig. 6. Typical reactions within leaves of soybean cultivars or lines exhibiting susceptible or resistant phenotypes following fixing, clearing, and staining with cotton blue. A, Hawaii 94-1, Tan reaction on cultivar Williams; B, Taiwan 80-2, Tan reaction on PI 230970; C, Hawaii 94-1, RB reaction on PI 230970; D, Taiwan 72-1, RB reaction on D86-8286; E, Puerto Rico 76, RB reaction on PI 230970; and F, Brazil 82-1, RB reaction on PI 230970. Note that the susceptible reactions (A and B) resulted in both large and small uredinia. Resistant RB reactions were typified by either a few small uredinia or complete lack of uredinia. being pursued in more detail in our current research.

Leaf pieces collected from greenhousegrown soybean plants 14 days after inoculation and stained with cotton blue produced results that were relatively easy to interpret, particularly when resistant and susceptible standards were included within the same experiment. For example, under highly favorable conditions for disease, a susceptible reaction was typified by a mean of 3 to 7 uredinia per lesion, and uredinia varied greatly in size within individual lesions (Fig. 6A and B). In contrast, in the same experiment, resistance was typified by a mean of only 0 to 2 small uredinia per lesion (Fig. 6C and D). A particularly useful criterion was that highly susceptible reactions had a wide range of uredinia sizes within the same lesion, whereas resistant reactions had only small uredinia (Fig. 6C and D), or in some instances no uredinia.

We examined inoculated soybean plants at 14 days after inoculation. It is possible that determination of uredinia numbers and diameters at times other than 14 days might have given somewhat different results, but it is unlikely that trends or main conclusions would differ. Numbers and sizes of uredinia are quantitative measurements, and as such probably would detect partial resistance (23). This hypothesis is being pursued in our research program.

Although potentially very valuable, microscopic examination of leaf tissue should not, as yet, replace examination of intact plants in a rust resistance-screening program. In our rust-screening program at Fort Detrick, we are now using histological measurements to support our observations in the greenhouse. Smaller and fewer uredinia are manifestations of at least one form of disease resistance. Although we did not critically compare spore production, observations in our greenhouse suggest, and logic dictates, that decreases in numbers and sizes of uredinia can greatly decrease spore production.

The differences in numbers and sizes of uredinia in a susceptible, typically Tan, reaction, compared with a resistant, $\mathrm{RB}$, reaction can be rationalized. After initial pathogen establishment in a susceptible reaction, the hyphae rapidly spread within the leaf tissue, producing new uredinia over an extended time period. This progression of pathogen development results in uredinia varying widely in maturities and, hence, size within individual lesions. Large uredinia often are present at the center, surrounded by smaller uredinia, sometimes in concentric circles. In contrast, pathogen development is restricted in a resistant reaction, resulting in fewer and smaller uredinia (e.g., Fig. 6C and D), and in some instances no uredinia. Indeed, resistance to soybean rust often can be detected merely by a quick visual examination of the stained leaf tissue. 
Soybean cultivars that display extreme reductions in the number and size of uredinia following inoculation with specific isolates of $P$. pachyrhizi probably result from the presence of a major resistance gene. More subtle differences may result from partial resistance, and detection likely will require more critical measurements. Although not part of this study, resistance to soybean rust could also be a result of reduced numbers of pathogen penetrations, resulting in fewer points of initial establishment in the host, leading to fewer lesions.

The Rpp 1-4 genes are believed to be race specific $(1,2,7,8)$. In Taiwan, three physiological races of $P$. pachyrhizi were identified by inoculating five differential soybean cultivars with 50 singleurediniospore isolates (34). In another study using 10 differential hosts, 42 rust isolates were differentiated into nine races (34). The investigators suggested that the predominate races in Taiwan possess multiple genes for virulence (34). Other rust isolates were reported to cause disease on all known suspected sources of specific resistance (31). Tschanz et al. (31) pointed out that the occurrence of multiple virulence genes in $P$. pachyrhizi was not what one would expect since no soybean lines were known to have more than one specific resistance gene for soybean rust. The presence of multiple virulence genes in $P$. pachyrhizi could make disease control strategies difficult (6).

Historically, genes conferring specific resistance to soybean rust rapidly became ineffective. For example, soybean cv. Komata, which contains the Rpp 1 gene, was found to be resistant in germ plasm evaluations in Australia in 1961 to 1963; however, by 1966, Tan-type lesions (susceptible reaction phenotype) were observed in field trials. By the mid 1970s, cv. Komata was considered no longer useful as a source of rust resistance (13). Similarly, soybean cv. Ankur, which contains the Rpp 3 gene resistant in India in the early 1970 s (29), was totally susceptible to rust by the 1980s (1).

Results from our study indicate races may also exist within $P$. meibomiae. Whereas Puerto Rico 76 infected all soybean accessions, producing an $\mathrm{RB}$ reaction, isolate Brazil 82-1 didn't produce symptoms (Immune reaction phenotype) on accessions with either Rpp 1 or Rpp 2 (Table 1). This indicates that these two $R p p$ genes also recognize avirulence genes in $P$. meibomiae, which might suggest that these avirulence genes either have coevolved or have been transferred between these two Phakopsora species.

There is evidence from our study that the new isolates are somewhat more virulent, and/or more aggressive, than the older isolates. In only two instances in experiment 3 were the spore producing areas per lesion, calculated by multiplying average number of uredinia per lesion $\times$ average cross-sectional area per uredinium, less than $5 \times 10^{3} \mu^{2}$. This equated to only $4 \%$ of the total number of rust reactions producing low-level sporulation. In contrast, in 14 instances with old isolates, equal to $25 \%$, the spore producing area per lesion was less than $5 \times 10^{3} \mu \mathrm{m}$.

With the recent discovery of $P$. pachyrhizi in the continental United States, it is important that efforts to screen for rust resistance be increased, and newly discovered resistance genes be incorporated into U.S. cultivars as quickly as possible. Since single gene, specific resistance appears to be of limited value, horizontal or ratereducing resistance is desirable. Evidence for such resistance in soybean exists $(31,33)$. Tolerance to soybean rust also has been identified $(6,27)$, and this trait should be incorporated into elite soybean cultivars in each of the maturity groups grown in the United States. Determining the number of uredinia per lesion and average uredinia diameters provides a direct and quantitative method to measure levels of rust resistance, and should be useful for identifying both specific and rate-reducing resistance. With modification, the methodology could be made more rapid, thus accommodating the testing of large numbers of soybean accessions.

This study confirms the presence of the $R p p$ genes and our ability to recognize reaction phenotypes in the original PIs. Evidence from this study suggests that D91-5987, derived from a cross between PI 459025, containing the Rpp 4 rust resistance gene, and the cultivar Hardee, lacks resistance to ASR. Other soybean lines, presumably containing rust resistance genes, in the past also gave indications of being either intermediate in reaction or completely susceptible. We found intermediate reactions difficult to score based on the current RB/Tan designations, and therefore believe that in many instances reactions must be quantitatively measured. The methodology described here, using histology, can be used to quantitate a resistance reaction and assist in correctly identifying rust resistance during development of resistant varieties. Histological measurements potentially will detect both specific and partial resistance.

\section{ACKNOWLEDGMENTS}

We thank X. B. Yang, Iowa State University, for his many helpful suggestions during the course of the study.

\section{LITERATURE CITED}

1. Bromfield, K. R. 1984. Soybean Rust. Monogr. No. 11. American Phytopathological Society, St. Paul, MN.

2. Bromfield, K. R., and Hartwig, E. E. 1980. Resistance to soybean rust and mode of inheritance. Crop Sci. 20:254-255.

3. Cai, S., and Tan, Y. 1994. Breeding and evaluation of new rust resistant soybean variety You 84-87. Pages 111-115 in: Advance of Soybean Rust Research. Edited by Dept. of Science \& Technology, MAPRC; Asian Regional Center,
AVRDC; and Oil Crops Research Institute, CAAS. Proceedings of a meeting held in 1992. Hubei Science and Technology Publishing House, Hubei, People's Republic of China.

4. Cherry, E., and Peet, C. E. 1966. An efficient device for the rapid collection of fungal spores from infected plants. Phytopathology 56:11021103.

5. Frederick, R. D., Snyder, C. L., Peterson, G. L., and Bonde, M. R. 2002. Polymerase chain reaction assays for the detection and discrimination of the soybean rust pathogens Phakopsora pachyrhizi and P. meibomiae. Phytopathology 92:217-227.

6. Hartman, G. L. 1996. I-B. Highlights of soybean rust research at the Asian Vegetable Research and Development Center. Soybean Rust Workshop, 9-11 August 1995. J. B. Sinclair and G. L. Hartman, eds. College of Agriculture, Consumer, and Environmental Sciences, National Soybean Research Laboratory Publ. No. 1, Urbana, IL.

7. Hartwig, E. E. 1986. Identification of a fourth major gene conferring resistance to soybean rust. Crop Sci. 26:1135-1136.

8. Hartwig, E. E., and Bromfield, K. R. 1983. Relationships among three genes conferring specific resistance to rust in soybeans. Crop Sci. 23:237-239.

9. Hennings, P. 1903. Some new Japanese Uredinales. IV. Hedwigia (Suppl.):107-108. (German text).

10. Kilen, T. C. 1997. Identification of a soybean breeding line resistant to rust in the Philippines. Soybean Genet. Newsl. 24:199-200.

11. Killgore, E., Heu, R., and Gardner, D. E. 1994. First report of soybean rust in Hawaii. Plant Dis. 78:1216.

12. Kingsolver, C. H., Melching, J. S., and Bromfield, K. R. 1983. The threat of exotic plant pathogens to agriculture in the United States. Plant Dis. 67:595-600.

13. Kochman, J. K. 1977. Soybean rust in Australia. Pages 44-48 in: Rust of Soybean - The Problem and Research Needs. R. E. Ford and J. B. Sinclair, eds. International Agricultural Publications, Manila, the Philippines.

14. Levy, C. 2005. Epidemiology and chemical control of soybean rust in southern Africa Plant Dis. 89:669-674.

15. Lin, Z. 1994. Soybean rust epidemic and its integrated control strategy. Pages 60-64 in: Advance of Soybean Rust Research. Edited by Dept. of Science \& Technology, MAPRC; Asian Regional Center, AVRDC; and Oil Crops Research Institute, CAAS. Proceedings of a meeting held in 1992. Hubei Science and Technology, Hubei, People's Republic of China.

16. Liu, K. C. 1966. Studies on soybean rust and its control. (In Chinese, English summary.) Taiwan Agric. Q. 2:92-100.

17. McLean, R., and Byth, D. E. 1977. Resistance of soybeans to rust in Australia. Pages 58-61 in: Rust of Soybean - the Problem and Research Needs. R. E. Ford and J. B. Sinclair, eds. Report of a Workshop held in Manila, the Philippines, February 28-March 4, 1977. College of Agriculture, University of Illinois at Urbana-Champaign.

18. McLean, R. J., and Byth, D. E. 1980. Inheritance of resistance to rust (Phakopsora pachyrhizi) in soybeans. Aust. J. Agric. Res. 31:951-956.

19. Miles, M. R., Frederick, R. D., and Hartman, G. L. 2003. Soybean rust: Is the U.S. soybean crop at risk? APSnet feature, June 2003. American Phytopathological Society, St. Paul, MN. Online publication.

20. Mo, J., Zhu, G., Chen, Y., Huang, L., and Sun, H. 1994. Preliminary survey and identification of soybean varietal resistance to rust. Pages 116-122 in: Advance of Soybean Rust Re- 
search. Edited by Dept. of Science \& Technology, MAPRC; Asian Regional Center, AVRDC; and Oil Crops Research Institute, CAAS. Proceedings of a meeting held in 1992. Hubei Science and Technology Publishing House, Hubei, People's Republic of China.

21. Morel, W., and Yorinori, J. T. 2002. Situacion de la roja de la soja en el Paraguay. Bol de Diulgacion No. 44. Ministerio de Agricultura y Granaderia, Centro Regional de Investigacion Agricola, Capitan Miranda, Paraguay.

22. Ono, Y., Buritica, P., and Hennen, J. F. 1992. Delimitation of Phakopsora, Physopella and Cerotelium and their species on Leguminosae. Mycol. Res. 96:825-850.

23. Parlevliet, J. E. 1979. Components of resistance that reduce the rate of epidemic development. Annu. Rev. Phytopathol. 17:203-222.

24. Patil, P. V., and Basavaraja, G. T. 1997. A prospective source of resistance to soybean rust. Karnataka J. Agric. Sci. 10(4):1241-1243.

25. Rossi, R. L. 2003. First report of Phakopsora pachyrhizi, the causal organism of soybean rust in the Province of Misiones, Argentina. Plant Dis. 87:102.

26. Schneider, R. W., Hollier, C. A., Whitam, H. K., Palm, M. E., McKemy, J. M., Hernandez, J. R., Levy, L., and DeVries-Paterson, R. 2005.
First report of soybean rust caused by Phakopsora pachyrhizi in the continental United States. Plant Dis. 89:774.

27. Shin, D. C., and Tschanz, A. T. 1986. Studies on physiological reactions of soybean cultivars tolerant and susceptible to rust (Phakopsora pachyrhizi Syd.). Korean J. Crop Sci. 31:440446.

28. Singh, B. B., Gupta, S. C., and Singh, B. D. 1974. Sources of field resistance to rust [Phakopsora pachyrhizi] and yellow mosaic diseases of soybean. Indian J. Genet. Plant Breed. 34:400-404.

29. Singh, B. B., and Thapliyal, P. N. 1977. Breeding for resistance to soybean rust in India. Pages 62-65 in: Rust of Soybean - The Problem and Research Needs. R. E. Ford and J. B. Sinclair, eds. Report of a Workshop held in Manila, the Philippines, February 28-March 4, 1977. College of Agriculture, University of Illinois at Urbana-Champaign.

30. Tan, Y. J., Yu, Z., and Yang, C. Y. 1996. Soybean Rust. China Agricultural Press, Beijing, China.

31. Tschanz, A. T., Wang, T. C., and Tsai, B. Y. 1986. Recent advances in soybean rust research at Asian Vegetable Research and Development Center. Pages 237-245 in: Soybeans in
Tropical and Subtropical Cropping Systems. S. Shanmugasundaram and E. W. Sulberger, eds Asian Vegetable Research and Development Center, Shanhua, Tainan, Taiwan.

32. Vakili, N. G., and Bromfield, K. R. 1976 Phakopsora rust on soybean and other legumes in Puerto Rico. Plant Dis. Rep. 60:995-999.

33. Wang, T. C., and Hartman, G. L. 1992. Epidemiology of soybean rust and breeding for host resistance. Plant Prot. Bull. 34:109-124.

34. Yeh, C. C. 1983. Physiological races of Phakopsora pachyrhizi in Taiwan. J. Agric. Res. China 32:69-74.

35. Yorinori, J. T., Paiva, W. M., Frederick, R. D., Costamilan, L. M., Bertagnolli, P. F., Hartman, G. E., Godoy, C. V., and Nunes, J., Jr. 2005. Epidemics of soybean rust (Phakopsora pachyrhizi) in Brazil and Paraguay from 2001 to 2003. Plant Dis. 89:675-677.

36. Yu, Z., Tan, Y., and Sun, Y. 1994. Distribution and damage of soybean rust in china. Advance of Soybean Rust Research. Edited by Dept. of Science \& Technology, MAPRC; Asian Regional Center, AVRDC; and Oil Crops Research Institute, CAAS. Proceedings of a meeting held in 1992. Hubei Science and Technology Publishing House, Hubei, People's Republic of China. 